Vol. 1, No. 1, March 2019 e-ISSN: 2656-4882 p-ISSN: 2656-5935

http://journal-isi.org/index.php/isi

Published By DRPM-UBD

\title{
Application of Naive Bayes Classifier Algorithm in Determining New Student Admission Promotion Strategies
}

\section{Penerapan Algoritma Naive Bayes Classifier Dalam Menentukan Strategi Promosi Penerimaan Mahasiswa Baru}

\author{
Ahmad Haidar Mirza ${ }^{1}$ \\ ${ }^{1}$ Informatics Department, Universitas Bina Darma, Palembang, Idnonesia \\ Email: ${ }^{1}$ haidarmirza@binadarma.ac.id
}

\begin{abstract}
Data Mining is a process that uses statistical techniques, mathematics, artificial intelligence, machine learning to extract and identify useful information and related knowledge from large databases. Data mining is the process of finding new patterns in data by filtering large amounts of data. Data mining uses pattern recognition technology that is similar to statistical techniques and mathematical techniques. The patterns found can provide useful information for generating economic benefits, effectiveness and efficiency. Algorithm Naive Bayes Classifier is one method of data mining that can be used to support effective and efficient promotion strategies. The Naive Bayes Classifier algorithm is used to predict the interest of the study based on the calculations performed. The data used are new student registration data from 2014 until 2016 at Bina Darma University. The results of this study are new models that are expected to provide important information can be used to assist the Marketing Team of Bina Darma University Palembang in policy making and implementation of appropriate marketing strategy. The results obtained are expected to help to support the promotion strategies that impact on the effectiveness and efficiency of promotion and increase the number of new students who will register.
\end{abstract}

Keywords: Data Mining, Naive Bayes, Classification

\section{PENDAHULUAN}

The introduction must contain a general background (shortly), a literature review (state of the art) in order to record the existing method/solutions, to show which is the best of previous researches and to show the main limitation of the previous researches. It has be contain with at least 5 literature in order to justify novelty this paper. The introduction should be clearly contain the gap analysis (why this research needs to be done? What is the uniqueness of this paper Seiring dengan 
perkembangan di era globalisasi dan kemajuan dibidang teknologi informasi yang cepat memberikan pengaruh yang cukup besar baik dalam bidang industri maupun dibidang pendidikan. Hal ini juga membawa suatu perubahan besar dalam tingkat persaingan antara instansi dan perusahaan. Banyak perusahaan dan instansi pemerintah yang menggunakan data mining untuk menggali informasi. Data mining adalah proses yang menggunakan teknik statistik, matematika, kecerdasan buatan, dan machine learning untuk mengekstraksi dan mengidentifikasi informasi yang bermanfaat dan pengetahuan yang terkait dari berbagai basis data besar [7]. Selain perusahaan dan instansi lainnya, penerapan data mining juga dilakukan dalam dunia pendidikan baik oleh perguruan tinggi negeri maupun swasta. Hal ini karena banyak perguruan tinggi yang berupaya untuk mendapatkan competitive intelligence.

Salah satu penerapan data mining dengan naive bayes classifier dalam perguruan tinggi adalah untuk mengetahui minat dan ketertarikan calon mahasiswa baru terhadap program studi yang tersedia dengan memprediksi probabilitas keanggotaan suatu class. Naive Bayes Classifier adalah pendekatan statistik yang fundamental dalam pengenalan pola (pattern recognition) Pendekatan ini didasarkan pada kuantifikasi trade-off antara berbagai keputusan klasifikasi dengan menggunakan probabilitas dan ongkos yang ditimbulkan dalam keputusankeputusan tersebut [3]. Informasi ini dapat digunakan untuk mendukung strategi promosi agar lebih efektif dan efisien. Sehingga perguruan tinggi dapat mengetahui serta menentukan target atau sasaran pasar dengan lebih rinci.

Ketersediaan data yang banyak dan kebutuhan akan informasi atau pengetahuan sebagai pendukung pengambilan keputusan untuk membuat solusi bisnis dan dukungan infrastruktur di bidang teknik informatika merupakan cikal- bakal dari lahirnya teknologi data mining. Penggunaan teknik data mining diharapkan dapat membantu mempercepat proses pengambilan keputusan, memungkinkan perusahaan untuk mengelola informasi yang terkandung didalam data transaksi menjadi sebuah pengetahuan (knowledge) yang baru. Dalam hal perencanaan kegiatan promosi guna peningkatan minat calon mahasiswa untuk mendaftar, Unit Pemasaran Universitas Bina Darma membutuhkan masukan - masukan guna meningkatkan minat lulusan Sekolah Menengah Atas (SMA) atau setara yang ada di kota Palembang pada khususnya dan di Sumatera Selatan pada umumnya untuk mejadi Mahasiswa Universitas Bina Darma, hal ini dikarenakan kegiatan promosi yang terdiri dari kegiatan pemasangan iklan, penyebaran brosur dan promosi dengan mengundang sekolah masih belum menyebar luas kedaerah-daerah yang tingkat peminatnya masih rendah sehingga masyarakat yang ada didaerah atau dipedesaan masih belum banyak yang mengetahui tentang Universitas Bina Darma. Dengan demikian, Unit Pemasaran Universitas Bina Darma Palembang perlu untuk menggali atau mencari informasi dari data pendaftaran tahun-tahun sebelumnya sebagai bahan evaluasi dan analisa untuk mendukung strategi promosi tahun berikutnya. Konsep bayesian classification ditujukan untuk memprediksi probabilitas di masa depan berdasarkan pengalaman di masa sebelumnya. 


\section{METODE}

\section{Metode Penelitian}

Metode penelitian yang digunakan adalah metode analisis deskriptif dengan pendekatan kuantitatif Menurut Sugiyono, dapat diartikan sebagai metode penelitian yang berlandaskan pada filsafat positivisme, digunakan untuk meneliti pada populasi atau sampel tertentu. Teknik pengambilan sampel pada umumnya dilakukan secara random, pengumpulan data menggunakan instrumen penelitian, analisis data bersifat kuantitatif / statistik dengan tujuan untuk menguji hipotesis yang telah ditetapkan [6]. Menurut Sugiyono [5] "Metode deskriptif adalah metode yang digunakan untuk menggambarkan analisis suatu hasil penelitian tetapi tidak digunakan untuk membuat kesimpulan yang lebih luas". Penelitian deskriptif merupakan suatu kegiatan yang dilakukan untuk menemukan pengetahuan mengenai objek dan subjek secara detail dalam kurun waktu tertentu. Selain itu penelitian dengan metode deskriptif juga merupakan penelitian yang bertujuan untuk menjelaskan, menggambarkan atau mendeskripsikan suatu keadaan objek, serta segala sesuatu terhadap variable - variable yang dapat dijelaskan baik secara hitungan angka maupun kata [5].

\section{Metode Pengumpulan Data}

Salah satu tahapan terpenting pada suatu penelitian yaitu pengumpulan data. Pengumpuan data merupakan kegiatan atau cara yang dapat diterapkan oleh peneliti dalam usahanya untuk mengumpulkan data yang dibutuhkan[1]. Selanjutnya dijelaskan oleh [2] bahwa pengumpulan data dapat dilakukan dengan cara pengamatan/observasi, wawancara, dokumentasi, serta gabungan/triangulasi. Pada penelitian ini menggunakan teknik pengumpulan data dengan melakukan pengamataan/observasi, pencarian dokumen, dan wawancara. Melakukan studi pustaka / studi literatur. Studi pustaka/studi literatur adalah suatu cara pengumpulan data dengan mempelajari teori yang berkaitan dengan cara membaca buku- buku/literatur, makalah maupun referensi- referensi.

\section{Metode Knowledge Discovery in Database (KDD)}

Data mining adalah proses yang menggunakan teknik statistik, matematika, kecerdasan buatan, dan machine learning untuk mengekstraksi serta mengidentifikasi informasi yang bermanfaat dan pengetahuan yang terkait dari berbagai basis data besar [1]. Dalam meningkatkan strategi promosi sangat memerlukan adanya proses data mining karena proses data mining sangat bermanfaat dalam mengambil informasi dari data base yang sudah ada. Istilah data 
mining dan Kowledge Discovery in Databases (KDD) menurut Kusrini [4], sering kali digunakan secara bergantian untuk menjelaskan proses penggalian informasi tersembunyi dalam suatu basis data yang besar. Sebenarnya kedua istilah tersebut memiliki konsep yang berbeda, tetapi berkaitan satu sama lain. Dan salah satu tahapan dalam keseluruhan proses KDD adalah data mining. Proses KDD (Knowlegge discovery in databases) secara garis besar dapat dijelaskan sebagai berikut:

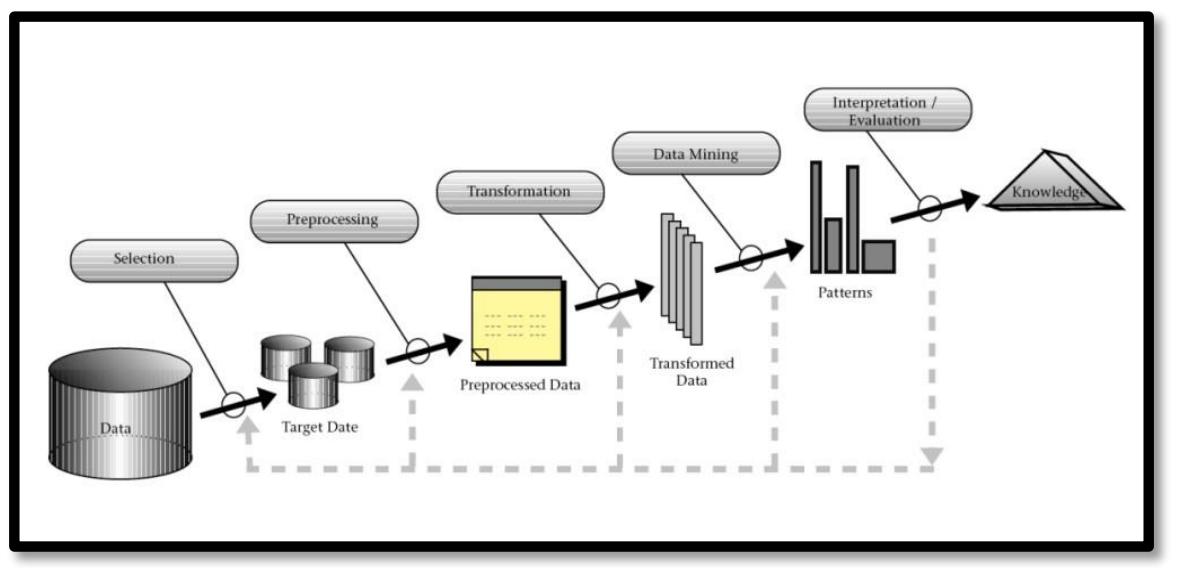

Gambar 1. Tahapan Knowledge Discovery in Databases [4]

\section{a. Data Selection}

Pemilihan (seleksi) data dari sekumpulan data operasional perlu dilakukan sebelum tahap penggalian informasi dalam knowledge data discovery (KDD) dimulai. Data hasil seleksi yang akan digunakan untuk proses data mining, disimpan dalam suatu berkas, terpisah dari basis data operasional.

\section{b. Preprocessing atau Cleaning}

Sebelum proses data mining dapat dilaksanakan, perlu dilakukan proses cleaning pada data yang menjadi fokus knowledge data discovery. Proses cleaning mencakup antara lain membuang duplikasi data, memeriksa data yang inkonsisten, dan memperbaiki kesalahan pada data, seperti kesalahan cetak juga dilakukan proses enrichment, yaitu proses memperkaya data yang sudah ada dengan data atau informasi lain yang relevan dan diperlukan untuk KDD, seperti data atau informasi.

\section{Transformation}

Coding adalah proses transformasi pada data yang telah dipilih, sehingga data tersebut sesuai untuk proses data mining. Proses coding dalam knowledge data discovery 
merupakan proses kreatif dan sangat tergantung pada jenis atau pola informasi yang akan dicari dalam basis data.

\section{Data mining}

Data mining adalah proses mencari pola atau informasi menarik dalam data terpilih dengan menggunakan teknik atau metode tertentu. Teknik, metode, atau algoritma dalam data mining sangat bervariasi. Pemilihan metode atau algoritma yang tepat sangat tergantung pada tujuan dan proses KDD secara keseluruhan.

\section{Interpretation atau evaluation}

Pola informasi yang dihasilkan dari proses data mining perlu ditampilkan dalam bentuk yang mudah dimengerti oleh pihak yang berkepentingan. Tahap ini merupakan bagian dari proses KDD yang disebut interpretation. Tahap ini mencakup pemeriksaan apakah pola informasi yang ditemukan bertentangan dengan fakta atau hipotesis yang ada pada sebelumnya.

Pola informasi yang dihasilkan dari proses data mining perlu ditampilkan dalam bentuk yang mudah dimengerti oleh pihak yang berkepentingan. Tahap ini merupakan bagian dari proses KDD yang disebut interpretation. Tahap ini mencakup pemeriksaan apakah pola informasi yang ditemukan bertentangan dengan fakta atau hipotesis yang ada pada sebelumnya

\section{HASIL DAN PEMBAHASAN}

\subsection{Analisis Data Mining}

Data yang akan digunakan pada proses data mining menggunakan Algoritma Nä̈ve Bayes merupakan data mahasiswa Penerimaan Mahasiswa Baru (PMB) untuk tahun 2014, 2015 dan 2016 yang merupakan gambaran secara nyata mengenai keadaan penerimaan mahasiswa baru untuk seluruh yang ada di lingkungan Universitas Bina Darma. Setelah data di dapat dari Unit Pelaksana Teknis - Sistem Informasi Manajemen (UPT-SIM) Universitas Bina Darma, maka data akan di standarisasi mengikuti proses tahapan data mining agar data tersebut layak dan dapat diolah menggunakan software pengolahan data mining RapidMiner . dengan menggunakan algoritma Nä̈ve Bayes.

\subsection{Proses Data Mining Knowledge Discovery in Database (KDD)}

a. Data Selection

Pada tahap ini data yang digunakan akan diseleksi dengan cara melihat kecenderungan data / kesesuaian data dengan topik / judul penelitian yang akan diteliti oleh penulis, dalam hal ini data yang di peroleh oleh penulis dari UPT-SIM sudah memiliki kesesuain format data yang terdiri dari atribut Tahun PMB, Nama, 
Vol. 1, No. 1, March 2019

Alamat, Asal_Sekolah, Progdi dan Status. Adapun atribut yang ada pada masing masing data sebagai berikut:

Tabel 1. Atribut Database PMB

\begin{tabular}{cll}
\hline No & \multicolumn{1}{c}{ Atribut } & \multicolumn{1}{c}{ Keterangan } \\
\hline 1 & Tahun PMB & Tahun dari Penerimaan Mahasiswa \\
\hline 2 & Nama & Nama Mahasiswa \\
\hline 3 & Alamat & Alamat Mahasiswa \\
\hline 4 & Asal_Sekolah & Asal Sekolah Mahasiswa \\
\hline 5 & Progdi & Program Studi yang di pilih oleh Mahasiswa \\
\hline 6 & Status & Status PMB Mahasiswa \\
\hline
\end{tabular}

\section{b. Data Pre Processing atau Data Cleaning}

Pada tahap ini akan dilakukan perbersihan data, yakni membuang data yang tidak konsisten dan noise/redudancy data. Pada data yang didapat, terdapat beberapa data yang tidak konsisten dan noise. Pada data tersebut diatas dapat dilihat adanya data yang kosong sehingga data tersebut harus di buang / hapus / delete agar pada saat proses klasifikasi dapat dilakukan perhitungan untuk proses data mining

\section{c. Data Integration}

Tahap integrasi data adalah tahap penggabungan data dari berbagai sumber. Dataset mahasiswa Penerimaan Mahasiswa Baru (PMB) Universitas Bina Darma berasal dari satu sumber yaitu Unit Pelaksana Teknis - Sistem Informasi Manajemen (UPT-SIM), dan dari data yang ada tersebut dapat digunakan untuk proses pengolahan data mining dengan menggunakan metode Naïve Bayes. Data ini terdiri dari data PMB untuk tahun 2014, 2015 dan 2016 yang kemudian digabungkan kedalam satu dataset untuk di ubah ke format CSV dengan menggunakan Ms. Excel yang nantinya akan di Import ke dalam Database Mysql untuk proses Data Manipulation

\section{d. Data Transformation}

Ada pun pada tahap ini data akan diubah menjadi bentuk yang sesuai untuk proses data mining. Karena dalam penelitian ini akan dilakukan uji coba secara teoritis dan mengunakan software data mining yaitu RapidMiner, maka data yang telah melalui proses sebelumnya akan di transformasi agar dapat sesuai dengan algoritma yang dipakai yaitu algoritma Naïve Bayes. Pada tahapan ini atribut yang di pakai akan diberi label mengikuti kondisi data - data pada atribut tersebut. Berikut tampilan hasil klasifikasi pada masing - masing atribut pada Mysql: 
Vol. 1, No. 1, March 2019

p-ISSN: 2656-5935 http://journal-isi.org/index.php/isi e-ISSN: 2656-4882

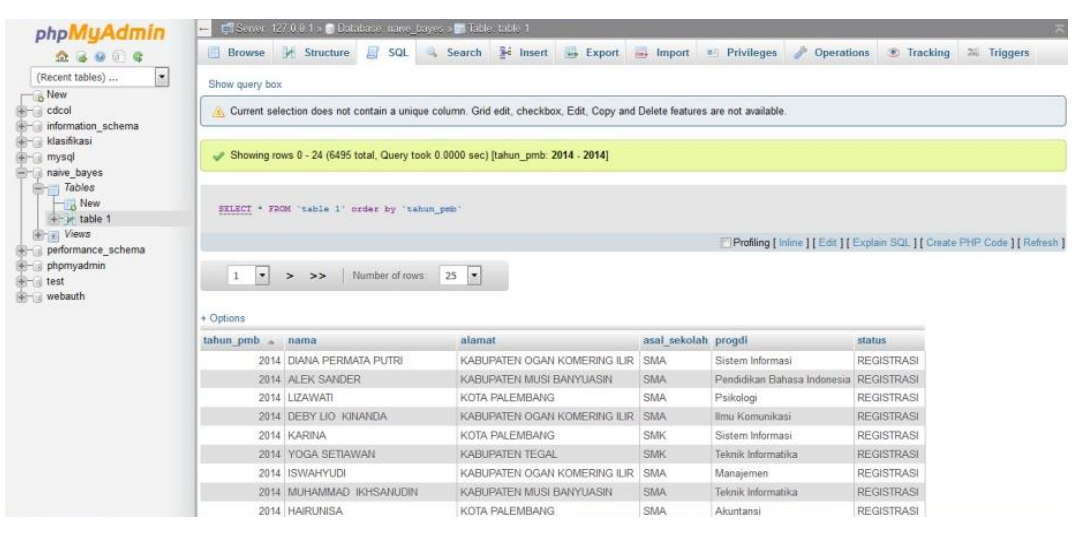

Gambar 2. Hasil dari Proses Klasifikasi Pada Masing - Masing Atribut

Setelah hasil proses klasifikasi tersebut, maka langkah selanjutnya yaitu mengubah format data hasil klasifikasi menjadi format CSV agar dapat di olah dengan menggunakan software data mining yaitu RapidMiner. Data yang sudah di dilakukan pada proses tahapan diatas ini adalah data yang sudah siap atau sudah bersih dari data yang redundancy dan data yang loss (Kosong) sehingga data tersebut bisa dilakukan proses data mining dengan naive bayes seperti pada proses tahap hasil selanjutnya. Berikut gambar dibawah yang siap untuk dilakukan proses data mining dengan naive bayes.

e. Data Mining dengan Naive Bayes

Berdasarkan hasil dari data set yang telah di klasifikasikan dan siap untuk di olah adapun hasil dari distribusi frekuensi data untuk perhitungan teoritis untuk algoritma Naïve Bayes dapat dilihat pada Tabel dibawah ini.

Tabel 2. Distribusi Frekuensi Data PMB

\begin{tabular}{|c|c|c|c|c|c|}
\hline \multirow{3}{*}{$\begin{array}{c}\text { Independent } \\
\text { Variabel }\end{array}$} & \multirow{3}{*}{ Value } & \multicolumn{4}{|c|}{ count } \\
\hline & & \multicolumn{3}{|c|}{ Tidak Registr } & \multirow{2}{*}{$\begin{array}{c}\text { Tidak Registr } \\
\text { asi }+1\end{array}$} \\
\hline & & $\begin{array}{c}\text { Registr } \\
\text { asi }\end{array}$ & asi & $\begin{array}{c}\text { Registr asi } \\
\quad+1\end{array}$ & \\
\hline \multirow[t]{8}{*}{ Alamat } & KABUPATEN AGAM & 3 & 0 & 4 & 1 \\
\hline & KABUPATEN ASAHAN & 1 & 0 & 2 & 1 \\
\hline & KABUPATEN BANGKA & 13 & 0 & 14 & 1 \\
\hline & KABUPATEN BANGKA BARAT & 19 & 2 & 20 & 3 \\
\hline & KABUPATEN BANGKA SELATAN & 9 & 0 & 10 & 1 \\
\hline & KABUPATEN BANGKA TENGAH & 1 & 0 & 2 & 1 \\
\hline & KABUPATEN BANGKALAN & 1 & 0 & 2 & 1 \\
\hline & KABUPATEN BANTUL & 1 & 0 & 2 & 1 \\
\hline
\end{tabular}

20 | Application of Naive Bayes Classifier Algorithm in Determining New..... 
Journal of Information Systems and Informatics

Vol. 1, No. 1, March 2019

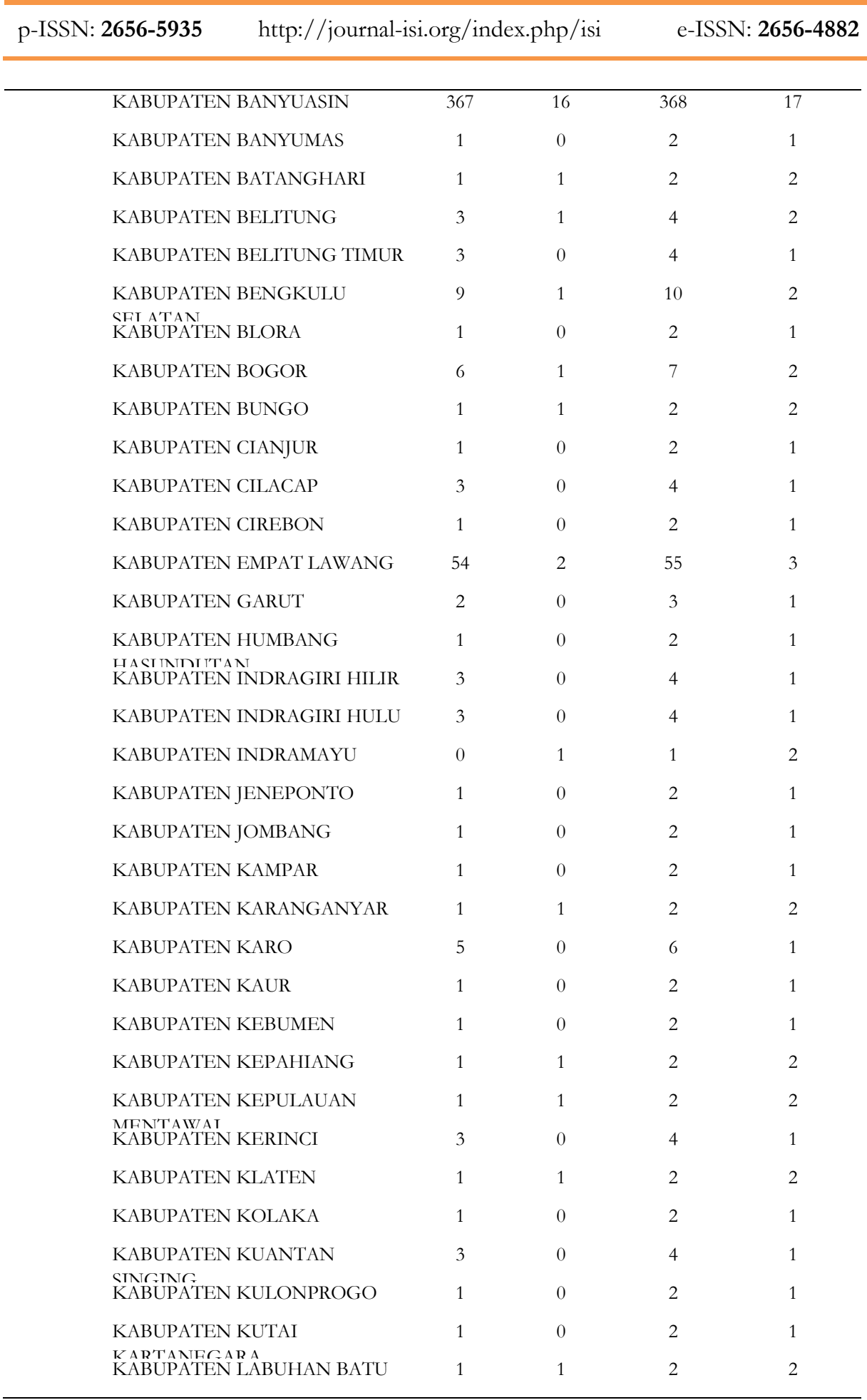


Journal of Information Systems and Informatics

Vol. 1, No. 1, March 2019

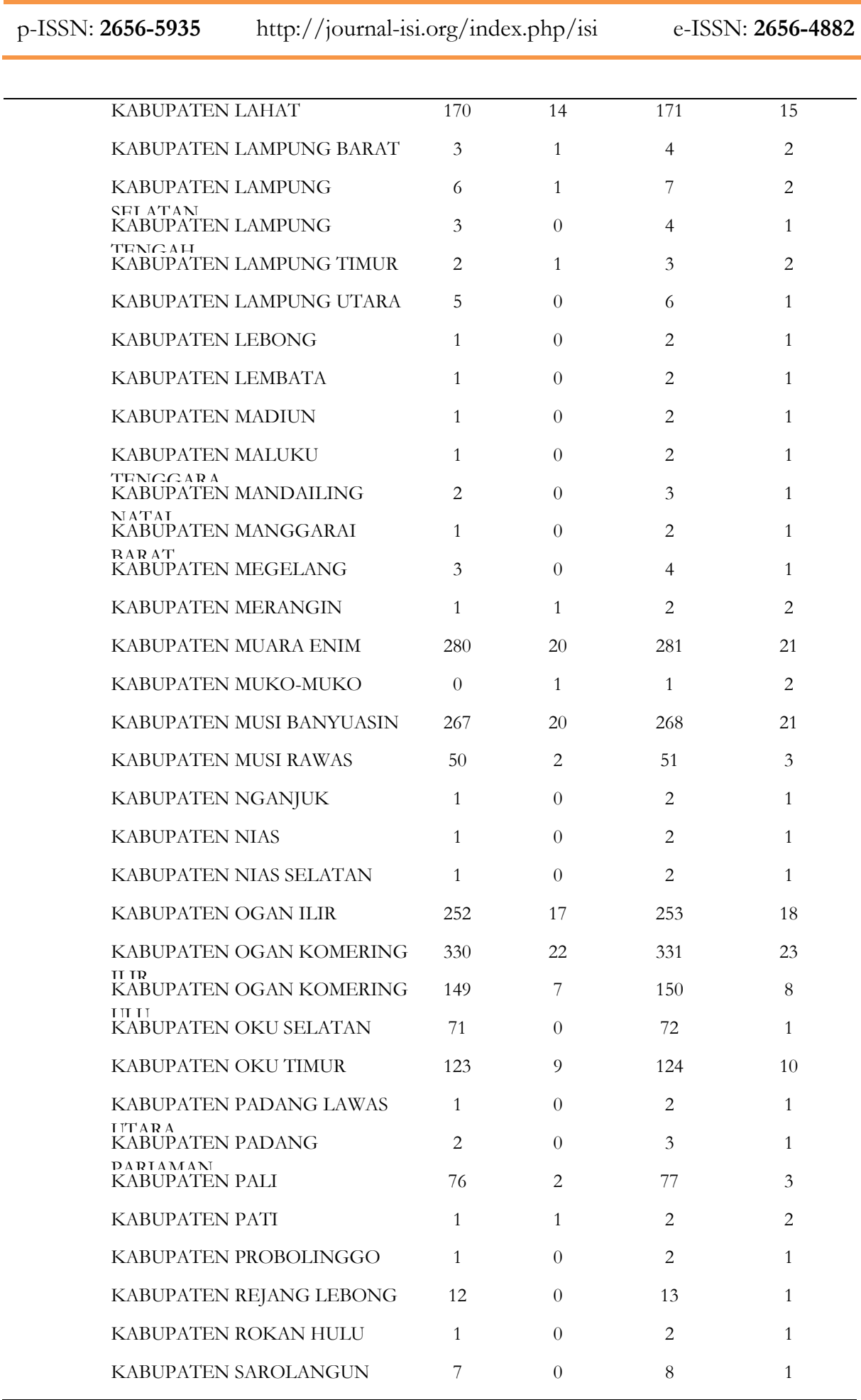

22 | Application of Naive Bayes Classifier Algorithm in Determining New..... 
Journal of Information Systems and Informatics

Vol. 1, No. 1, March 2019

\begin{tabular}{|c|c|c|c|c|}
\hline p-ISSN: 2656-5935 & \multicolumn{2}{|c|}{ rg/index.php/isi } & \multicolumn{2}{|c|}{ e-ISSN: 2656-4882 } \\
\hline KABUPATEN SELUMA & 1 & 0 & 2 & 1 \\
\hline KABUPATEN SEMARANG & 3 & 0 & 4 & 1 \\
\hline KABUPATEN SERANG & 2 & 0 & 3 & 1 \\
\hline KABUPATEN SIAK & 1 & 0 & 2 & 1 \\
\hline KABUPATEN SIDOARJO & 1 & 0 & 2 & 1 \\
\hline KABUPATEN SIMALUNGUN & 1 & 0 & 2 & 1 \\
\hline KABUPATEN SIMEULUE & 1 & 0 & 2 & 1 \\
\hline KABUPATEN SLEMAN & 3 & 0 & 4 & 1 \\
\hline KABUPATEN SOLOK & 4 & 1 & 5 & 2 \\
\hline KABUPATEN SRAGEN & 2 & 0 & 3 & 1 \\
\hline KABUPATEN SUBANG & 1 & 0 & 2 & 1 \\
\hline KABUPATEN SUMEDANG & 2 & 0 & 3 & 1 \\
\hline KABUPATEN TANGGAMUS & 2 & 0 & 3 & 1 \\
\hline KABUPATEN TANJUNG JABUNG & 4 & 0 & 5 & 1 \\
\hline $\begin{array}{l}\text { RARAT } \\
\text { KABUPATEN TANJUNG JABUNG }\end{array}$ & 1 & 0 & 2 & 1 \\
\hline $\begin{array}{l}\text { TIMIR } \\
\text { KABUPATEN TAPANULI }\end{array}$ & 1 & 0 & 2 & 1 \\
\hline $\begin{array}{l}\text { CEIATANT } \\
\text { KABUPATEN TASIKMALAYA }\end{array}$ & 3 & 0 & 4 & 1 \\
\hline KABUPATEN TEGAL & 1 & 0 & 2 & 1 \\
\hline KABUPATEN TEMANGGUNG & 1 & 0 & 2 & 1 \\
\hline KABUPATEN TOBA SAMOSIR & 1 & 0 & 2 & 1 \\
\hline KABUPATEN TULANG BAWANG & 3 & 1 & 4 & 2 \\
\hline KABUPATEN WAJO & 1 & 1 & 2 & 2 \\
\hline KABUPATEN WAY KANAN & 7 & 0 & 8 & 1 \\
\hline KOTA BANDA ACEH & 1 & 0 & 2 & 1 \\
\hline KOTA BANDAR LAMPUNG & 11 & 4 & 12 & 5 \\
\hline KOTA BANDUNG & 4 & 3 & 5 & 4 \\
\hline KOTA BANJAR & 1 & 0 & 2 & 1 \\
\hline KOTA BATAM & 5 & 0 & 6 & 1 \\
\hline KOTA BEKASI & 2 & 0 & 3 & 1 \\
\hline KOTA BENGKULU & 7 & 1 & 8 & 2 \\
\hline KOTA BUKITTINGGI & 2 & 1 & 3 & 2 \\
\hline КОТА СIMАНI & 5 & 0 & 6 & 1 \\
\hline KOTA DEPOK & 1 & 1 & 2 & 2 \\
\hline KOTA DUMAI & 2 & 1 & 3 & 2 \\
\hline KOTA JAKARTA BARAT & 3 & 0 & 4 & 1 \\
\hline
\end{tabular}


Journal of Information Systems and Informatics

Vol. 1, No. 1, March 2019

\begin{tabular}{|c|c|c|c|c|c|}
\hline p-ISSN: 2656-5935 & \multicolumn{3}{|c|}{ http://journal-isi.org/index.php/isi } & \multicolumn{2}{|c|}{ e-ISSN: 2656-4882 } \\
\hline & KOTA JAKARTA PUSAT & 1 & 0 & 2 & 1 \\
\hline & KOTA JAKARTA SELATAN & 2 & 0 & 3 & 1 \\
\hline & KOTA JAKARTA TIMUR & 3 & 2 & 4 & 3 \\
\hline & KOTA JAKARTA UTARA & 3 & 0 & 4 & 1 \\
\hline & KOTA JAMBI & 23 & 3 & 24 & 4 \\
\hline & KOTA KENDARI & 1 & 0 & 2 & 1 \\
\hline & KOTA LUBUK LINGGAU & 63 & 7 & 64 & 8 \\
\hline & KOTA MADIUN & 1 & 0 & 2 & 1 \\
\hline & KOTA MANADO & 1 & 0 & 2 & 1 \\
\hline & KOTA MEDAN & 2 & 0 & 3 & 1 \\
\hline & KOTA METRO & 2 & 0 & 3 & 1 \\
\hline & KOTA PADANG & 9 & 0 & 10 & 1 \\
\hline & KOTA PADANG SIDEMPUAN & 1 & 0 & 2 & 1 \\
\hline & KOTA PAGAR ALAM & 88 & 5 & 89 & 6 \\
\hline & KOTA PALEMBANG & 3273 & 178 & 3274 & 179 \\
\hline & KOTA PANGKAL PINANG & 12 & 0 & 13 & 1 \\
\hline & KOTA PEMATANG SIANTAR & 2 & 0 & 3 & 1 \\
\hline & KOTA PRABUMULIH & 167 & 13 & 168 & 14 \\
\hline & KOTA SALATIGA & 1 & 0 & 2 & 1 \\
\hline & KOTA SIBOLGA & 1 & 0 & 2 & 1 \\
\hline & KOTA SURABAYA & 6 & 0 & 7 & 1 \\
\hline & KOTA SURAKARTA & 1 & 0 & 2 & 1 \\
\hline & KOTA TANGERANG & 5 & 2 & 6 & 3 \\
\hline & KOTA YOGYAKARTA & 2 & 2 & 3 & 3 \\
\hline & & 6119 & 376 & 6120 & 377 \\
\hline Asal Sekolah & SMA & 4393 & 243 & 4394 & 244 \\
\hline & SMK & 1472 & 106 & 1473 & 107 \\
\hline & MADRASAH & 256 & 25 & 257 & 26 \\
\hline & & 6121 & 374 & 6122 & 375 \\
\hline Progdi & Administrasi Bisnis & 81 & 6 & 82 & 7 \\
\hline & Akuntansi & 676 & 45 & 677 & 46 \\
\hline & Ilmu Komunikasi & 197 & 15 & 198 & 16 \\
\hline
\end{tabular}

24 Application of Naive Bayes Classifier Algorithm in Determining New.... 
Journal of Information Systems and Informatics

Vol. 1, No. 1, March 2019

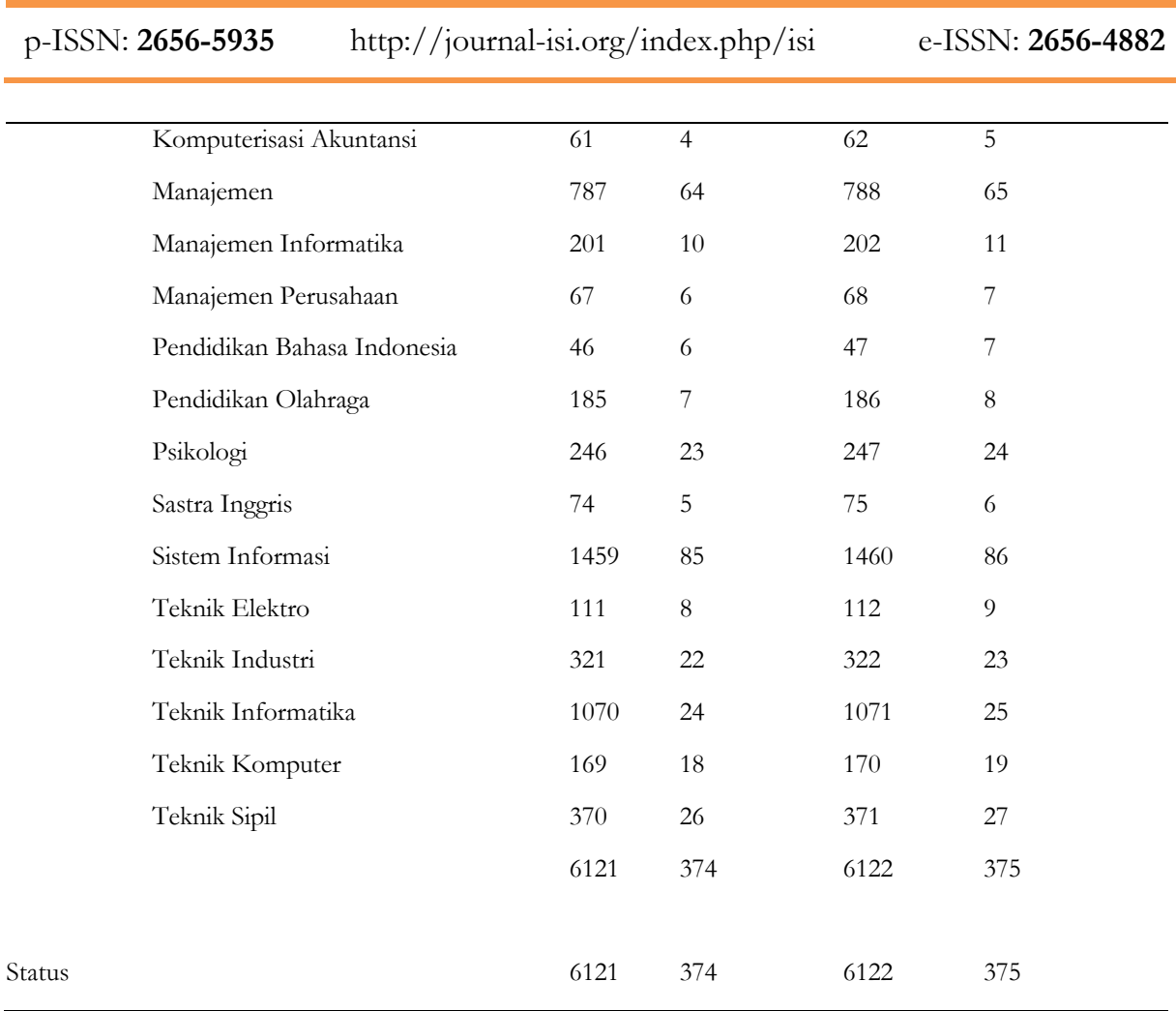

Hasil perhitungan simple distribution data dari tabel distribusi frekuensi perhitungan teoritis untuk Status Registrasi dan Status Tidak Registrasi sebagai berikut :

$\begin{array}{ll}\mathrm{P}(\text { REGISTRASI }) & =(6122 / 6495)=0.942 \\ \mathrm{P}(\text { TIDAK REGISTRASI }) & =(375 / 6495)=0.057\end{array}$

\section{f. Proses Pengujian Data}

Setelah di dapat hasil simple distribution maka dapat dilakukan proses pengujian berdasarkan Persamaan dari teorema Bayes adalah:

$$
P(H \mid X)=\frac{P(H \mid X) \cdot P(H)}{P(X)}
$$

Dimana:

$\mathrm{X}$ : Data dengan kelas yang belum diketahui

$\mathrm{H}$ : Hipotesis data X merupakan suatu kelas spesifik

$\mathrm{P}(\mathrm{H} \mid \mathrm{X})$ : Probabilitas hipotesis $\mathrm{H}$ berdasar kondisi X (posterior probability) $\mathrm{P}(\mathrm{H})$ :

Probabilitas hipotesis $\mathrm{H}$ (prior probability) 
$\mathrm{P}(\mathrm{X} \mid \mathrm{H})$ : Probabilitas $\mathrm{X}$ berdasarkan kondisi pada hipotesis $\mathrm{H} \mathrm{P}(\mathrm{X})$ : Probabilitas $\mathrm{X}$, Diketahui : $\mathrm{X} 1=$ Alamat, $\mathrm{X} 2=$ Asal Sekolah X3 = Program Studi $\mathrm{Y}=$ Status

\section{Proses Pengujian 1}

Jika Diketahui Alamat $=$ Palembang, Asal Sekolah $=$ SMA, Progdi $=$ Sistem

Informasi.

$\mathrm{P}($ REGISTRASI $)=(6122 / 6495)=0.942$

$\mathrm{P}($ TIDAK REGISTRASI $)=(375 / 6495)=0.057$

\section{Pengujian}

$\mathrm{P}($ Palembang $\mid$ REGISTRASI $)=3274 / 6122=0.535$

$\mathrm{P}($ Palembang $\mid$ TIDAK REGISTRASI $)=179 / 375=0.477$

$\mathrm{P}($ SMA $\mid$ REGISTRASI $)=4394 / 6122=0.717$

$\mathrm{P}($ SMA $\mid$ TIDAK REGISTRASI $)=244 / 375=0.513$

$\mathrm{P}($ Sistem Informasi $\mid$ REGISTRASI $)=1460 / 6122=0.238$

$\mathrm{P}($ Sistem Informasi $\mid$ TIDAK REGISTRASI $)=86 / 375=0.229$

\section{HMAP Kesimpulan :}

$$
\begin{aligned}
\mathrm{P}(\text { REGISTRASI }) & (3274 / 6122) *(4394 / 6122) * \\
& (1460 / 6122) *(6122 / 6495)=0.0860 \\
\mathrm{P}(\text { TIDAK REGISTRASI })= & (179 / 375) *(244 / 375) *(86 / 375) *(375 / 6495) \\
= & 0.0031
\end{aligned}
$$

Kesimpulan P (REGISTRASI) > P (TIDAK REGISTRASI) sehingga Calon Mahasiswa dengan kriteria tersebut dapat di prediksi Registrasi.

\section{Proses Pengujian 2}

Jika Diketahui Alamat $=$ Agam, Asal Sekolah $=$ SMA, Progdi $=$ Sistem Informasi $\mathrm{P}($ REGISTRASI $)=(6122 / 6495)=0.942$

$\mathrm{P}($ TIDAK REGISTRASI $)=(375 / 6495)=0.057$

\section{Pengujian}

$\mathrm{P}($ Agam $\mid$ REGISTRASI $)=4 / 6122=0.00065$

$\mathrm{P}($ Agam $\mid$ TIDAK REGISTRASI $)=1 / 375=0.002666$

$\mathrm{P}($ SMA $\mid$ REGISTRASI $)=4394 / 6122=0.717$ 
$\mathrm{P}($ SMA $\mid$ TIDAK REGISTRASI $)=244 / 375=0.513$

$\mathrm{P}($ Sistem Informasi $\mid$ REGISTRASI $)=1460 / 6122=0.238$

$\mathrm{P}($ Sistem Informasi $\mid$ TIDAK REGISTRASI $)=86 / 375=0.229$

HMAP Kesimpulan :

$\begin{array}{lll}\mathrm{P}(\text { REGISTRASI }) & (4 / 6122) *(4394 / 6122) * \\ & (1460 / 6122) *(6122 / 6495)= \\ & 0.000104486 \\ \mathrm{P}(\text { TIDAK REGISTRASI })= & (1 / 375) *(244 / 375) *(86 / 375) *(375 / 6495) \\ & =0.00001785\end{array}$

Kesimpulan P(REGISTRASI) $>\mathrm{P}($ TIDAK REGISTRASI) sehingga Calon Mahasiswa dengan kriteria tersebut dapat di prediksi Registrasi.

Berdasarkan data hasil dan pembahasan diatas dapat kita jadikan sebagai acuan untuk menentukan strategi promosi pada Universitas Bina Darma Palembang dengan melihat data atribut dari Alamat, Asal Sekolah dan Program Studi. Dimana dari data Penerimaan Mahasiswa Baru (PMB) dari tahun 20142016 dengan jumlah data 6495 yang registrasi 6121 dan tidak registrasi 374. Dari atribut alamat data mahasiswa yang mendaftar tertinggi adalah beralamat Kota Palembang dengan jumlah pendaftar 3273, yang mendaftar berdasarkan tingkat sekolah asal adalah SMA dengan jumlah pendaftar 4393 dan pilihan jurusan yang tertinggi adalah Program Studi Sistem Informasi dengan jumlah 1459. Jadi dalam menetukan strategi promosi yang harus kita lihat adalah dari alamat dan asal sekolah yang tingkat pendaftar rendah, dan yang lebih harus ditonjolkan di Universitas Bina Darma adalah Program Studi yang pendaftarnya rendah, Sehingga pendaftar akan tertarik dengan Universitas Bina Darma Palembang.

\section{KESIMPULAN}

Adapun kesimpulan dari penelitian ini dalam memprediksi proses REGISTRASI dan TIDAK REGISTRASI mahasiswa menggunakan data set yang sudah melalui tahap awal Knowledge Dciscovery in Database (KDD) sebanyak 6495 record yang diambil dari data penerimaan mahasiswa baru tahun 2014, 2015 dan 2016 sebagai berikut:

1) Proses pengolahan data mining menggunakan atribut alamat dengan klasifikasi berdasarkan nama kota / nama kabupaten, atribut asal sekolah yang di klasifikasi berdasarkan pendidikan SMA, SMK dan MADRASAH, atribut progdi yang diklasifikasikan berdasakan program studi dari masing - masing fakultas yang ada dilingkungan Universitas Bina Darma dan atribut status sebagai label dalam proses pengolahan data mining dengan klasifikasi REGISTRASI DAN TIDAK REGISTRASI. 
2) Model data mining di buat menggunakan software pengolahan data mining yaitu Rapidminer, dengan hasil nilai Probalitas untuk REGISTRASI yaitu 0.942 dengan pembulatan nilai menjadi 0.94 dan nilai probabilitas untuk TIDAK REGISTRASI yaitu 0.057 dengan pembulatan nilai menjadi 0.058.

3) Model data mining yang di hasilkan pada Rapidminer dapat memprediksi hasil dengan beberapa kriteria klasifikasi berdasarkan klasifikasi yang dibuat menurut atribut masing - masing mampu menilai seorang calon Mahasiswa Baru.

4) Dengan menggunakan metode Naïve Bayes Classifier mampu menunjukkan informasi yang tersembunyi pada data atribut - atribut yang digunakan dalam proses pengolahan data mahasiswa pada proses Penerimaan Mahasiswa Baru (PMB) di Universitas Bina Darma serta memberikan solusi untuk membuat strategi promosi dengan melihat alamat, asal sekolah, dan progdi pilihan dari calon mahasiswa baru.

\section{REFERENSI}

[1]. Arikunto, Suharsimi. 2011. Prosedur Penelitian: Suatu Pendekatan Praktik. Edisi Revisi VII. Jakarta: PT. Rineka Cipta.

[2]. Basuki, Sulistyo. 2006. Metode Penelitian. Jakarta: Wedatama Widya Sastra.

[3]. Budi, Santoso, 2007, Data Mining : Teknik Pemanfaatan Data untuk Keperluan Bisnis, Graha Ilmu, Yogyakarta

[4]. Kusrini dan Luthfi. E. Taufiq.(2009).Algoritma Data Mining. Yogyakarta: Andi. Laksana, Fajar. 2008. Manajemen Pemasasaran : Pendekatan Praktis. Edisi Pertama. Cetakan Pertama. Graha Ilmu. Yogyakarta.

[5]. Setyosari, Punaji. 2010. Metode Penelitian dan Pengembangan. Jakarta: Kencana

[6]. Sugiyono. 2012. Metode Penelitian Kuantitatif Kualitatif dan R\&D. Bandung: Alfabeta.

[7]. Turban, E., dkk, 2005, Decicion Support Systems and Intelligent Systems, Andi Offse

[8]. www.binadarma.ac.id , website Universitas Bina Darma Palembang pada tanggal 29-05-2016

28 | Application of Naive Bayes Classifier Algorithm in Determining New..... 